\title{
Bipedalism, pelvic-spinal balance and cranial facial development
}

\author{
C. Bazert' ${ }^{1}$, D. Vidal' ${ }^{2}$, M. El Okeily ${ }^{3}$ \\ 1 Qualified specialist in Dentofacial Orthopedics, Private Practitioner, \\ Master of Conferences of the Universities of Bordeaux \\ 2 Qualified specialist in Dentofacial Orthopedics, Private Practitioner \\ 3 Maxillofacial Surgeon, Private Practitioner
}

\section{SUMMARY}

The transition to human bipedalism and the verticalization process are essentially marked by the extension of the hip and the straightening of the trunk by sacral inclination and lumbar lordosis. These phenomena resemble those observed in children during the transition from crawling to walking.

Deep cranial facial morphological modifications accompany the evolution of the axial skeleton throughout hominization. Can a child's postural development influence his/her cranial facial architecture in the same way? Through an anthropological and orthopedic approach, we will attempt to bring forth some answers and to specify the link with our professional practice.

\section{KEYWORDS}

Hominization, bipedalism, pelvic incidence, lordosis, cranial facial posture, prognathism, static balance

\begin{abstract}
Evolution into human bipedalism required major anatomical changes: the human body gradually specialized from head to foot to standing upright, bipedal walking, and bipedal running. The inherent constraints in this type of locomotion (compression and parasagittal movements) have contributed to decreased balance, requiring skeletal modifications but also an improvement of the nervous system for energy-saving purposes. The influence of the Earth's gravity was
\end{abstract}

essential, and the axial skeleton has transformed in response to gravity constraints ${ }^{5}$.

With the exception of human beings, no primate has signs of specialization to bipedalism. The comparison with other primates, and more specifically the great apes, highlights the morphological differences in each skeletal stage. These differences, which are related to each other, offer to bipedal humans a position of stability, balance, and energy conservation. 
In the verticalization process, special attention must be given to the changes of the sacroiliac area of the pelvis and the acquisition of the cervical and lumbar lordosis ${ }^{22}$.

The pelvis (or the pelvic girdle) ensures the a stable link between the spine and the lower limbs. Its morphology and orientation have a major role in human sagittal balance.

The pelvis consists of three bones: the sacrum, which is a low spinal segment, in the midline, and the two iliac bones, to the side as well as the front. The latter are connected to the sacrum on the back through the sacroiliac joints, and are connected to each other at the pubic symphysis. The whole pelvis forms a slightly oval ring whose outline is slanted downward and forward. Mobility between the sacrum and the iliac bones is very limited because of the particular shape of the sacroiliac joints and the dense ligament bracing that firmly reinforce the pelvis ${ }^{14}$.

The S1 upper plateau (first sacral vertebra) is a pedestal on which the spine rests. In the sagittal plane, it is normally located slightly behind the vertical line, running through the hip joint.

It is also a mobile structure able to perform rotations, inclinations, or versions.

Thanks to the pelvic parameters described by many authors, including Duval-Beaupère ${ }^{16}$, it is possible to define and study pelvic geometry by observing three parameters: pelvic version, sacral tilt, and pelvic incidence (Fig. 1).

- Pelvic version is defined as the angle between the vertical and a line connecting the center of femoral heads and the center of the sacral plateau. This parameter reflects the position of the pelvis in space, more or less tilted forward or backward around a

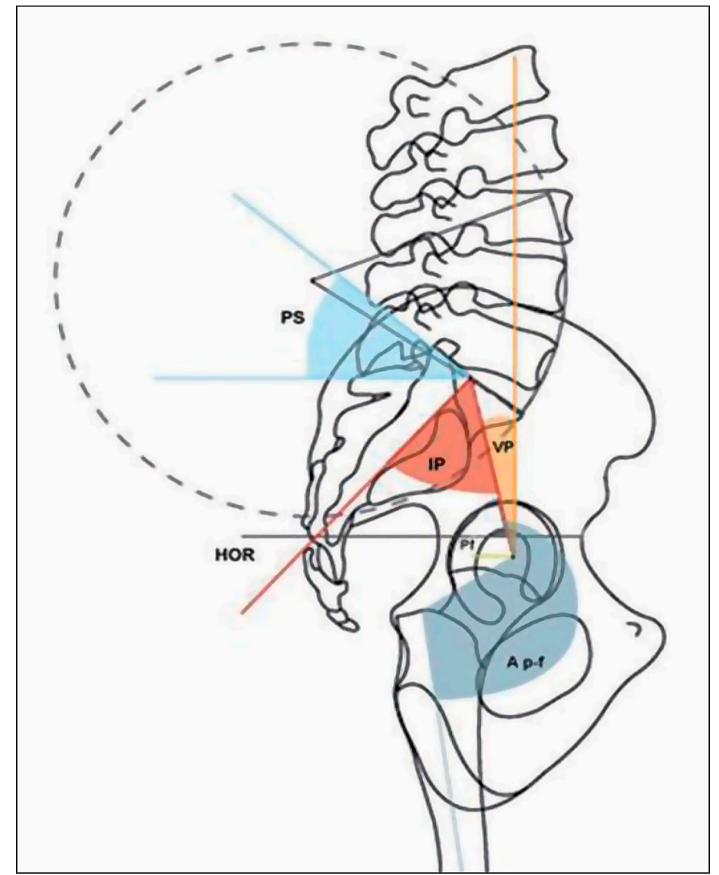

Figure 1

Common variables pelvic region. PS: sacral tilt; IP: pelvic incidence; VP: pelvic version;

A p-f: misalignment angle; HOR: true horizontal. (D. Vidal).

transversal axis through the two femoral heads. In a standing position, the normal angle of pelvic version, open to the rear, Is $13^{\circ} \pm 6^{\circ}$ (Vialle $\left.{ }^{46}\right)$. While standing in the normal position, the pelvis rests slightly tilted forward. The greater the increase in the angle of pelvic version, the more the body's center of gravity is projected at the back of the femoral heads ${ }^{8}$. There is an increase in pelvic version when the pelvis undergoes retroversion, while it decreases when the pelvis undergoes anteversion.

1. The second parameter is the sacral tilt, which corresponds to the angle representing the orientation of the sacral plateau to the horizontal. The more or less pronounced inclination of the sacral tilt conditions 
the position of the overlying lumbar spine. Its normal value is $41^{\circ} \pm 8^{\circ}$ (Vialle $\left.{ }^{46}\right)$.

2. Finally, pelvic incidence corresponds to the sum of pelvic version and sacral tilt. The value obtained is a constant for a given individual, irrespective of position. Its normal value is $55^{\circ} \pm 10^{\circ}$ $\left(M_{0}{ }^{32}\right)$. When pelvic version increases, sacral tilt decreases, and vice versa. Overall, the greater the pelvic incidence, the more accentuated the sacral tilt, the more the pelvis projects forward, and the more lumbar lordosis is accentuated in compensation.

Mangione and Sénégas ${ }^{30}$ emphasize the major role of hip extension et sacrum horizontalization in the evolution process in the context both of the species (phylogenesis) and of each individual (ontogenesis). For them, the pelvis represents the hinge of the lumbar-pelvic complex, and is modified by two opposing actions:

3. Hip extension (under the action of the gluteal muscles), which allows the pelvis to verticalize.

4. The contraction of multifidus (sacrospinalis and sacrolumbalis), which are inserted through a thick membrane on the sacral spines, allowing to maintain the trunk in a vertical position and contributing to accentuate the sacrum skewness that will generate a lumbar lordosis proportional to such skewness, so the set may be balanced.

These two opposing actions at the level of the pelvis lead to the widening of the sacroiliac angle (the sciatic tuberosity bears witness to the traction of the sacrum on the iliac bone by the sacrospinous ligament). It actually matches the angle of pelvic incidence.
Thus, in comparing the pelvis of humans and great apes, it is possible to observe that angle of pelvic incidence has increased gradually, drawing the sacrum back to the hip joints.

The sacrum allows the transition of the forces generated in the body to the pelvis. It is a welded, reinforced piece to support the weight of the body (viscera and torso).

The morphology of the sacrum is thus modified in comparison to that of large-sized apes. As such, in humans, a shorter, wider sacrum in anteversion is observed, with horizontalization of the sacral base; a more laterally developed sacral wing; a kidney-shaped auricular surface, and larger dimensions (sacroiliac joint) (Fig. 2).

The enlarged iliac wing has allowed a larger insertion area of the gluteal muscles (which are extensions of the thigh in bipedalism) on the pelvis, thus enabling standing on one foot. These gluteal muscles, more bulky and powerful, form a good part of the human buttocks, and set humans apart from the great apes. Our pelvis is very short and broad, under pressure. Large-sized apes have a pelvis under tension ${ }^{45}$.

In humans, the vertebral column is more vertical. The thoracic cage of large-sized apes is conical. In humans, the thorax is expanded and flattened from the front to the back, with a somewhat diminished kyphosis of the thoracic spine, drawing the axis closer to the center of the body, which subsequently draws the line of gravity. These modifications are required morphological characteristics for better balance in an upright posture ${ }^{5,22}$.

In all nonhuman primates, only two spinal curvatures are observed: one is cervical, which is short and convex 
forward; the other one is dorsolumbar, which is rigid, wide, and convex backward. Humans, in contrast, display compensating curves: convex forward in the cervical and lumbar regions (lordosis) and convex backward in the dorsal and sacral sections (kyphosis) (Fig. 2).

Furthermore, there is a lower number of lumbar vertebrae in large-sized apes (3-4 vertebrae against five vertebrae in man and small-sized apes) and the ends of the articular processes draw, from a dorsal perspective, a geometric shape that develops differently from L3-L5 in chimpanzees and humans. In the latter, a square or rectangular shape, with a large vertical axis, meets

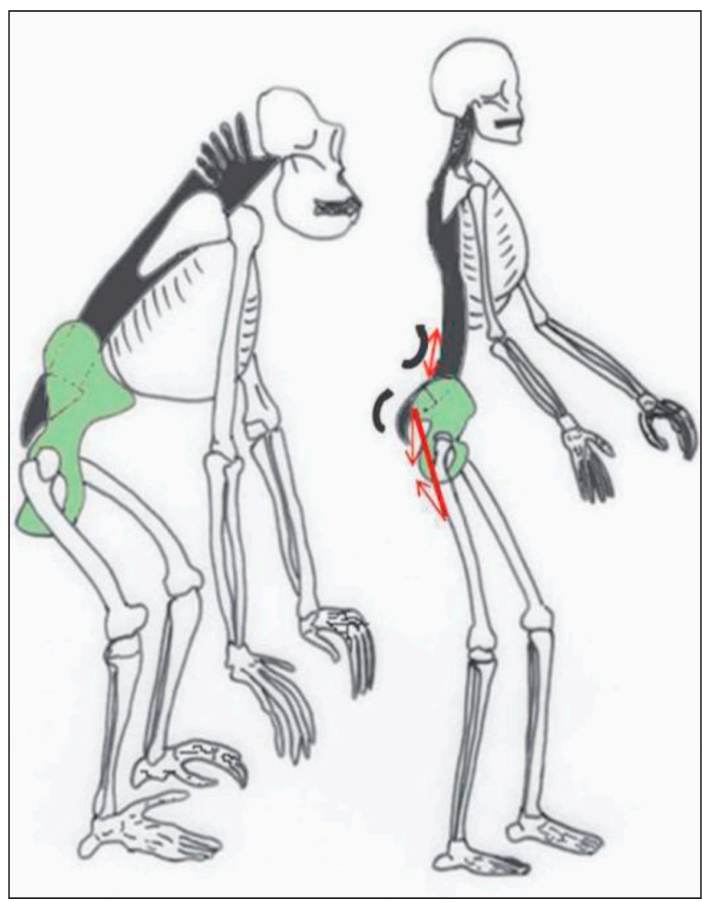

Figure 2

Verticalization of the human pelvis and hip extension by the action of the gluteal muscles. Anteversion of the sacrum and formation of lumbar lordosis under the influence of the erector spinae muscles. Reduction of the pelvis height and facial prognathism. (After drawing of H. Waterhouse in Joly). for upper lumbar while it turns into a rectangle with a large horizontal axis for lower lumbar. In chimpanzees, the shape remains triangular at the lower apex. This shape development from $L 3$ to $L 5$ reflects the presence of a lumbar lordosis ${ }^{5,22}$.

The human lumbar vertebrae are therefore much larger than those of other primates, to adapt to important mechanical stresses experienced by this segment of the column. The lumbar segment is also broader.

Lumbar lordosis changes the coverage of the femoral heads, allowing for a perfectly vertical standing position by the full extension of the hip and knee.

Nonhuman primates walk with flexed knees and hips. Large-sized apes present an inability to hip extension. In humans, in upright position, these joints are at maximum extension. The femurs, tibias, and fibulae are longer, and the femoral trochlea has a concave fossa to stabilize the patella during walking. In addition, the femurs are converging and form an angle with the axes of the tibia, referred to as the physiological genu valgum. It decreases the distance between two one-footed stance phases when walking. Among the great apes, the femur is almost parallel to the axis of the body, ${ }^{5,22}$.

The foot has lost its grip function. It is dedicated to balance and propulsion of the body during locomotion. The human foot has the particularity of being a musculotendinous arch, a veritable shock absorber and propeller ${ }^{15}$.

Thus, in a profile perspective, the energy-saving balance of the trunk on both lower limbs is a critical point for a biped. The curvatures of the vertebral spine and the hip joints must place themselves in an energy-efficient 
manner in relation to the gravity line of the trunk to create appropriate lever arms of gravity and resistance muscle forces. Gravity must be harmoniously distributed on both sides of the vertebral curvatures $5,22,47$.
It is the harmonious distribution and normal parameters of pelvic incidence, sacral tilt, lumbar lordosis, and dorsal kyphosis that ensures energy efficiency and balance. Any change in a parameter results in a change to all others.

\section{ACQUISITION OF THE UPRIGHT POSTURE IN CHILDHOOD AND SPINAL GROWTH}

Newborns and infants present only a single concave sagittal curvature toward the front (kyphosis). Later, in the first months after birth, as children begin to raise their head and sit, cervical lordosis develops. It is initiated by the posterior cervical muscles and ends when the child knows how to sit up ${ }^{49}$.

The thoracic and lumbar curvatures are formed in association with the verticalization of the pelvis, which is horizontal during the crawling period. Finally, the lumbar lordosis appears with walking, giving the vertebral column its final form.

It is essentially the posterior hip muscles (hip extensor gluteal muscles), the erector spinae muscles in the lumbar region, and the sacrotuberous and sacrospinal ligaments that contribute to this mechanism. Three movements then operate: hip extension, trunk modification (responsible for the accentuation of the lumbar curvature to posterior concavity), curvature of the sacrum as during the process of hominization.

The level of lumbar curvature progressively increases in children at the same time that the sacral tilt and the angle of pelvic incidence increase. At around 3 years of age, lumbar lordosis reaches the adult configuration. A reshaping of the intervertebral disks is then observed, but rather because of significant morphological changes in the vertebrae.

At around 5 years of age, dorsal kyphosis begins to be established (this will last up to 20 years). At around 8 years of age, lumbar lordosis increases, and at around ${ }^{15}$ years of age for girls and 20 years of age for boys, the spinal curvatures stabilize to the adult state ${ }^{26}$ (Fig. 3).

The normal value ${ }^{46}$ of thoracic kyphosis is $40^{\circ} \pm 10^{\circ}$. For lumbar lordosis in humans, the normal value is $41^{\circ} \pm 11^{\circ}$ loverall, it is more pronounced in its caudal portion ${ }^{37}$ ). Approximately 50\%$75 \%$ of the lumbar lordosis is located between $\mathrm{L} 4$ and $\mathrm{S} 1^{46}$.

The growth of the spine is rapid during the first 3 years of life, then experiences a slowdown between ages 7 and 10 , prior to a development peak during puberty. Spinal growth ends in general at a bone age of 16 for girls and 18 for boys.

The growth in the length of the spine occurs by endochondral ossification of the vertebral bodies, primarily dependent on genetic and hormonal factors, and growth in the antero-posterior direction mainly occurs by periosteal apposition phenomena subject mainly to mechanical factors ${ }^{49}$. 


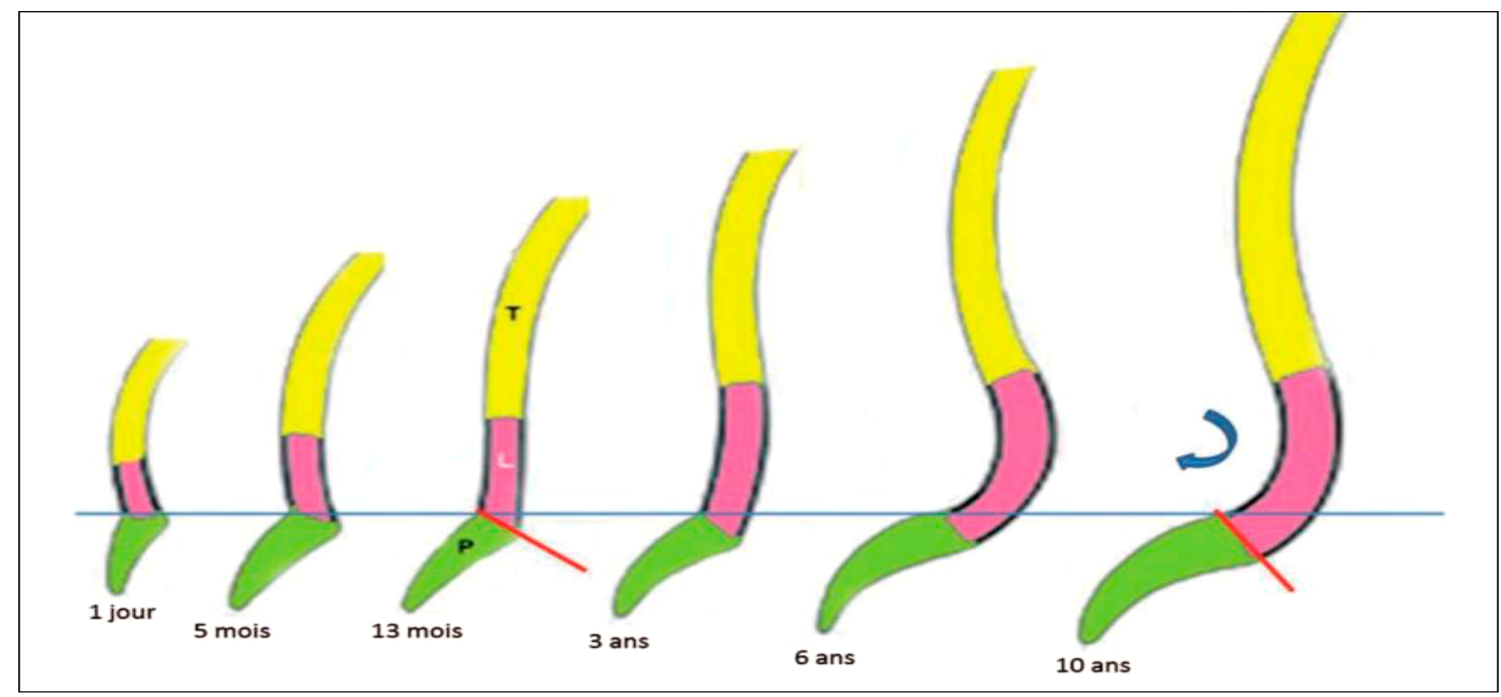

Figure 3

Age and establishment of spinal curvatures. (After T.A. Willis in Kapandji).

The prepubertal phase, if the child is frequently in lumbar hyperlordosis with pelvic anteversion and accentuated sacral tilt (misalignment is $<2.5 \mathrm{~cm}$ or sometimes even in the front of the center of the femoral heads, which means a more forward position of the pelvis in relation to the femoral heads); this arrangement is attenuates in young adults until it is reversed during middle and old age. Then knee flexion and thoraco-lumbar kyphosis appear. The center of gravity of the body moves backward to a position closer to the femoral heads ${ }^{13}$.

\section{POSTURAL CONTROL AND SAGITTAL SPINAL BALANCE}

The vertebrae represent body segments that articulate with one another. In the rest position, the centers of mass of each of these segments does not move in relation to each other. On one hand, a stable posture requires that the articulations between body parts are immobilized by the action of ligaments, muscles, and fascia; the standing position requires spine stabilization by powerful spine muscles that straighten, stabilize, and immobilize it ${ }^{5,7}$.

On the other hand, a stable posture requires that the spinal curvatures of reverse direction are offset to maintain the body's axis of gravity in a vertical line, which runs through the sustentation polygon that corresponds to the projected body limits on the ground. This line of gravity that unites all segmental mass centers is a vertical line that descends from the posterior edge of the odontoid, in front of the thoracic spine, then behind the lumbar spine, and then slightly behind back of the femoral heads ${ }^{21}$.

There is high variability in the population to achieve this sagittal balance, and multiple factors of psychological, 
social, or historical order are likely to interfere ${ }^{21}$. Humans are never perfectly motionless but rather continuously perform small rebalancing movements, allowing the maintenance of the projection of the center of gravity within the sustentation polygon ${ }^{40,7}$

Postural control not only enables to maintain a given position but also allows movement by providing a stable base of support for the action. Muscle tone, essentially the tone of extensor

\section{CRANIOFACIAL EVOLUTION}

Postural changes related to hominization and upright standing have modified head carriage and deeply influenced craniofacial morphology.

Therefore, in humans, when compared to the great apes, the following are frequently described ${ }^{12}$ :

- The general expansion of the neurocranium with increase of its capacity, frontal reshaping, increase in the biparietal diameter, and posterior shifting of the occipital bone;

- Flexion of the skull base with progressive closing of the sphenoidal angle, lowering and horizontalization of the foramen magnum. It is therefore located further under the skull. This position is followed by a significant development of occipital plate in connection with a wider and more powerful insertion of cervical musculature. The action of these muscles allows upturn of the head and horizontalization of the gaze. Thus, the orbital plane (which joins the upper and lower orbital edges) is perpendicular to the ground and at the level of the foramen magnum; muscles, is the main component of antigravity forces and postural control ${ }^{19}$.

The brainstem is involved in regulating the position of the head. It is a function of labyrinthine stimuli, cervical and muscle proprioception, visual and somatosensory stimuli. The whole of this information generates reactions of balancing and control of the center of gravity position, whether static or dynamically, in response to linear and angular accelerations during movement.

- The shrinking of the face from the skull, the increase in its total height (Fig. 2); the total change of the purpose of the mandible and the oral cavity, which, from a gripping, chewing, and defense role, is assigned a role of verbalization and language, and the power of chewing diminishes little by little.

Similarly, during ontogeny, changes in the cephalic morphology of the infant during the first months of life follow the progressive changes in its locomotion mode and craniospinal statics. The posteroinferior occipital shift and the folding of the skull base that occurs as a result of head remodeling, correlatively lead to brachycephalization and the lengthening of the face. These changes are observed in the first months of life, until the child is able to remain well seated, and especially once a stable erect posture is acquired ${ }^{11}$. These phenomena continue to a lesser degree throughout growth.

All these changes follow the change of constraint that appears around the 
cephalic pole, which is balanced over the spine. The atlanto-occipital joint moves closer to the center of gravity of the head (located a little behind the sella turcica, above and slightly ahead of the external ear canal). The remodeled skull rests more securely on the atlas, whose articular surfaces adapt to those of the occipital bone.
The upper articular facets of $\mathrm{C} 1$, in two parts, are characteristic to the human species ${ }^{16,13}$.

The cervical spine is at a right angle with the skull base, which is also characteristic to the human species, and it is long and mobile. Thus, the head is clear of the shoulders and can move independently of the trunk.

\section{CRANIOCERVICAL POSTURE AND FACIAL MORPHOLOGY}

The analysis of various studies $^{39,27,41,33,42,29,35}$ allows to highlight correlations between mandibular hypodivergence, reduction of anterior heights and enlargement of posterior heights of the face, flexion of the posterior section of the skull base, length of enlarged skull base, facial prognathism, tilted foramen magnum downward and backward, flexion of the skull base relative to the cervical spine, great height of the posterior arch of the atlas, a more posterior tilt of the upper cervical column, and increased cervical lordosis.

Other authors ${ }^{43,44,3}$ have noted a predominance of cervical abnormalities (fusion block, atlas occipitalization...) in apneic subjects and a connection between the spinal pathology and mandibular hyperdivergence or mandibular retrognathy with the opening of the skull base; the latter is especially important in cases where spinal fusion occurs in the lower cervical spine. The authors thus suggest an influence of changes in the cervical curvature and tilt of its different segments in the genesis of maxillofacial and ventilatory disorders.

D'Attilio $^{10}$ and Garcia $^{20}$ note that Class-II subjects feature an extension of the head relative to the upper cervical spine. It often follows an anterior tilt of the cervical spine in its lower part especially as mandibular divergence is increased. This promotes the maintenance of the posterior position of the mandible because of the tension of cervical structures (suprahyoid and infrahyoid muscles, respiratory, and intestinal tracts...).

In these studies, Class-III subjects present a posterior tilts of the lower cervical spine and diminished cervical lordosis. Cervical lordosis decreases in patients with a long jaw and it is observed mainly the lower part of the spine (C4-C7), which is significantly less lordotic in these subjects. It would seem that the size and position of the mandible are two factors strongly related to the cervical posture ${ }^{18}$.

The craniocervical relationship also seems related to the magnitude of thoracic kyphosis, as hyperkyphotic subjects show a compensation an extension of the head relative to the cervical spine $^{51}$, and marked cervical lordosis ${ }^{6,47}$. According to Hellsing ${ }^{24}$, the thoracic spine continues from the low cervical. Thoracic kyphosis may be related to increased facial prognathism and more 
significant mandibular body length, but the strength of the bonds is low.

The correlations between the values of thoracic kyphosis and lumbar lordo-

\section{PELVI-LUMBO-CRANIAL RELATIONS}

Roussouly et al. ${ }^{38}$ have highlighted the existence of four large groups of spinal curvatures depending on the amplitude of pelvic incidence (PI).

- Type I is characterized by low PI $\left(<45^{\circ}\right)$, short lumbar lordosis concentrated on L-S1, then long thoracolumbar kyphosis.

- Type II has also low PI, but lumbar lordosis and thoracic kyphosis are similar, long, and with low amplitude.

- Type III (PI $>45^{\circ}$ ) has a wider base, and lumbar lordosis and thoracic kyphosis are large and balanced. It is the most common type in the asymptomatic normal population.

- Type IV has also high PI, sometimes very high, and is characterized by a very wide lumbar lordosis offset by thoracic kyphosis also very wide (Fig. 4).

Are there craniofacial morphologies specific to these four lumbar-pelvic organizations?

Vidal $^{48}$, in a study on 58 EOS radiographs of the whole body, does not highlight the link between the intermaxillary offsets and the values of postural parameters of the pelvic region.

For Duval-Beaupère and Legaye ${ }^{16}$, there is a vertical chain that includes the following parameters: pelvic version, misalignment, Pl, sacral tilt, lumbar lordosis, and thoracic kyphosis. sis are not studied in detail seem to be positive but with weak bond8. The same is true for those connecting cervical lordosis and lumbar lordosis ${ }^{24}$.

When $\mathrm{Pl}$, unique to each individual, is large, sacral tilt is important, necessitating a deep lumbar lordosis and pronounced kyphosis. In the case of pelvic version, it also important and through a large misalignment, the sacrum (then shifted and very curved) is positioned back from the femurs and vice versa. Thus, the amount of $\mathrm{PI}$ largely determines the spread of spinal curvatures, from very curved spines to flat spines.

Following the spinal curvature, the line of gravity has its lever arm on the lumbar vertebrae and the femurs be adapted to a degree of lumbar lordosis and the pelvis' position in anteroversion or retroversion. The adaptation will take place using the chain of curves. For Duval-Beaupère ${ }^{17}$, the study of parameters, sagittal curves, and misalignment allows to account for the sagittal sway of the thoracolumbar spine above the pelvis. At the thoracic level, it is common to measure the T9 sagittal curves corresponding to the angle formed by the vertical line and the straight line that connects the center of the T9 vertebra T9 and the bilateral coxofemoral axis. Its normal value ${ }^{46}$ is $10^{\circ} \pm 3^{\circ}$. The center of gravity of the trunk supported by the femoral heads is located $15 \mathrm{~mm}$ in front of the ventral edge of $\mathrm{Tg}^{16}$. The more the curve decreases, the more the trunk has a tendency to shift forward. The more the T9 sagittal curve increases and the 


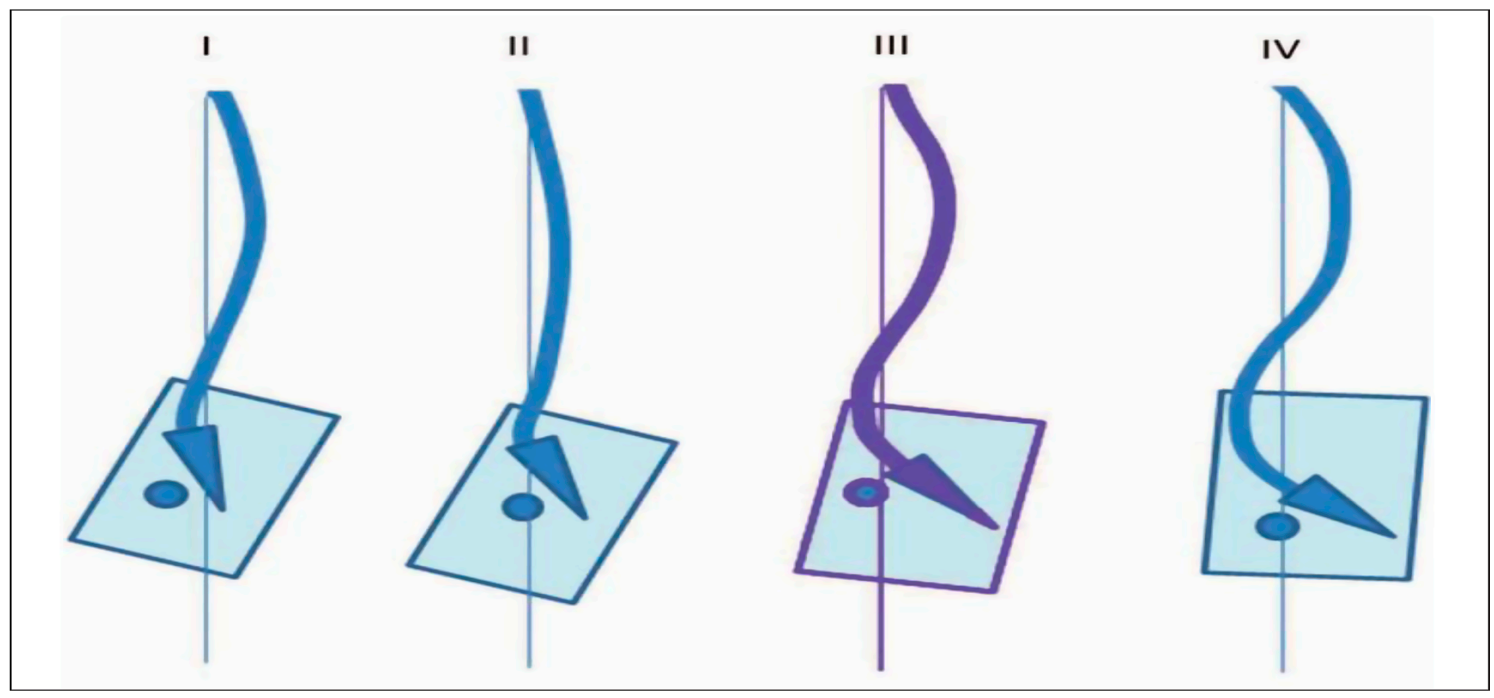

Figure 4

Pelvic-spinal correlations. Four types of spinal curvatures depending on the importance of Pl. (After Roussouly).

more the spine falls backward between T9 and the center of the femoral heads through a greater misalignment. The curve in T1 also varies in the same direction but to a more limited extent. It is an adjustment of the sagittal balance by a sagittal sway of the different segments of the spine above the pelvis.

As such, two extreme models ${ }^{47}$ of craniospinal organization may be distinguished. One shows pelvic anteversion, very sharp curvatures, mandibular hypodivergence, or a tendency to skeletal Class-II of maxillary origin, and a more anterior position of the ground projection of the body's center of gravity, offsetting the increase in T9 curve. The other shows pelvis retroversion, attenuated spinal curvatures, a tendency to skeletal Class III of maxillary origin or to more pronounced vertical facial growth and a center gravity projected on the ground more posteriorly because of a decrease in T9 deposit, which results in a more forward position of the spine above the femoral heads.
These models are closer to those defined by Delmasin ${ }^{28}$ or Kapandji26. The latter describes a model called "asthenic" (or static for Delmas) with accentuated spinal curvatures and pelvic anteversion that resembles the glossoptotic subject described by Robin, and a model called "sthenic" (or dynamic for Delmas) which has the opposite characteristics ${ }^{28}$ (Fig. 5).

These semantics also reflects the importance of the muscular chains in postural control.

The development of curvatures is involuntary, and it is influenced by muscular strength, notably abdominal muscle strength. Nonconformity to a compensatory arrangement (obesity, professional attitudes, therapeutic constraints...) may cause muscular pain or vertebral overload ${ }^{28}$.

A contracting muscle is in equilibrium with its antagonist. An injury or an inability to relaxation or contraction prevents the accurate execution of the movement. Thanks to a sophisticated 


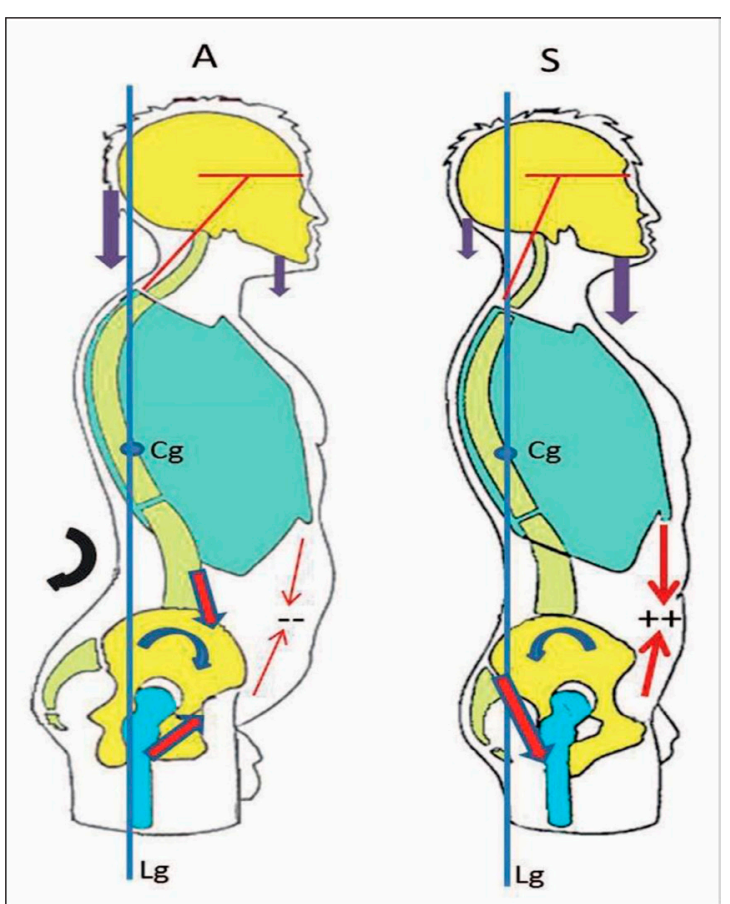

Figure 5

A: "asthenic" subject with pelvic anteversion, accentuated spinal curvatures, weak abdomen, cervical spine tilt, extension of the head relative to the spine. S: "sthenic" subject with pelvic retroversion, attenuated spinal curvatures, tone the abdominal and gluteal muscles, more remodeled cervical spine, flexion of the head relative to the spine, more posterior line of gravity compared to the femoral heads. (Inspired by Kapandji)

neurological regulation, the body can perform self-correction. As such, during malocclusion, it can modulate the activity of the chewing muscles to develop a new oral closing track and avoid premature contact. We can then observe muscle imbalances including the muscles connecting the head to the neck, and neck to body².

Daoulas et al. ${ }^{9}$, in a work on the influence of the increase in the thickness of shoe heels and podiatry heels, take a reverse path. The electromyographic study showed a significant increase of the electrical activity of the trapezius, suprahyoid, and masseter muscles. The anterior tilt of the body (observed by stabilometry) because of the effect of the heels $(4,8,24 \mathrm{~mm})$ is an extension of the head by the action of the trapezius muscles and tension of the suprahyoid muscles, unquestionably favoring higher jaw tilt, an equivalent mechanism to that adopted by mouth breathers for better ventilation. This highlights the potential upward impact, a disorder or a postural therapy on craniofacial development.

The adaptations that occur both at the muscle and joint levels can become lesions with the significance and duration of the imposed constraints. Among growing subjects, they can also lead to morphological adaptations related to increased tension in the muscle insertion sites and joint capping and remodeling tissues.

This mechanism has been highlighted more easily in the association between scoliosis and facial or occlusal asymmetry, but it is far less studied in the association of profiles.

The primary interest in dentofacial orthopedics to know these elements of balance and general posture lies in better etiological diagnosis of the dysmorphia observed and their development. We have an important role in a progressively younger consulting patient population, who we follow during much of the growth and especially on the pubertal period (the period for the appearance of scoliosis, for example), whose whole-body photographs can be easily obtained, and on whom we can perform systematic radiological examination of the whole cervical spine. In addition, as appropriate, we can prescribe full-spine $x$-rays if our review indicates the need. 
The second interest is to try to better understand the remote impact of our therapeutic intervention. Although studies increase, this top-down relationship is missing. The evaluations of osteopaths or orthopedists, often on the load on the spine, are not enough. A study by stabilometry ${ }^{4}$ we had conducted on the influence of the mandibular propulsion by brace showed a disruption of general static (increased fluctuation of the center of gravity) and a more posterior repositioning of the center of foot pressure. Two X-ray studies on the influence of Class-II (mainly because of an advanced jaw) and Class-III (essentially because of an advanced jaw) orthognathic surgeries show a decrease in sacral tilt and therefore pelvic retroversion, which could be explained by the anterior displacement of the facial center of gravity as a result of the advance of one of the two jaws, changing the balance of the intersupported lever described by Vital ${ }^{50}$ (Fig. 7). Lumbar and cervical lordosis are significantly attenuated in the case of Class-II correction, no doubt because of the cervical curvature and tensioning of suprahyoid and infrahyoid muscles following mandibular advancement. They promote flexion of the head and the relaxation of the neck extensors that control the important aspects of cervical lordosis and its anterior inclination ${ }^{23,34}$ (Fig. 6).

In the course of the phylogeny, with verticalization of the body, humans have seen a decline in facial prognathism and cervical tilt, and a forward pelvis shift. That is the exact opposite of what we observe when surgery results in increased facial prognathism (maxillary advancement in Class \|\|$^{1,31}$ and especially mandibular advancement in classes II): there is an increase in the anterior cervical tilt and pelvic retroversion ${ }^{25,36}$ perhaps in compensation to the more anterior positioning of the cephalic pole and perhaps involved in the maintenance of visual and labyrinthine postural sensors in their initial orientation ${ }^{34}$.
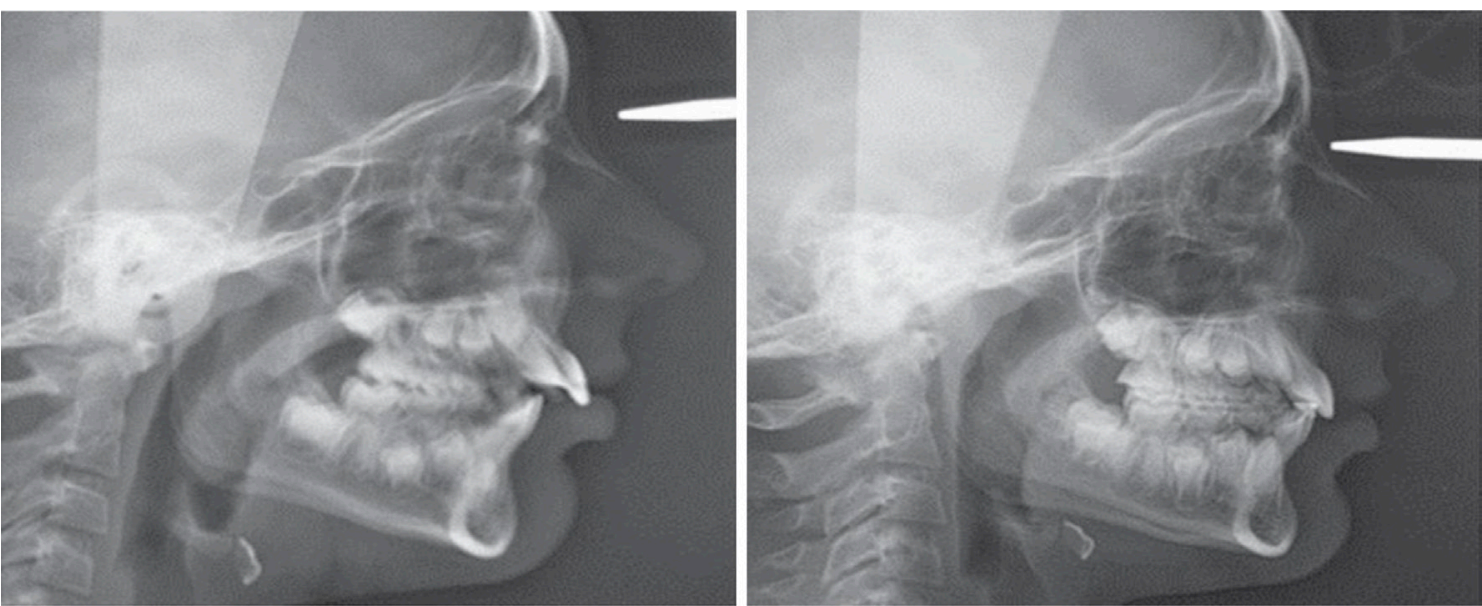

Figure 6

Orthopedic correction by Herbst booster on a mandibular retrognathy gutter. Reduction of the anterior tilt of the cervical spine and the extension of the head compared to the spine. 

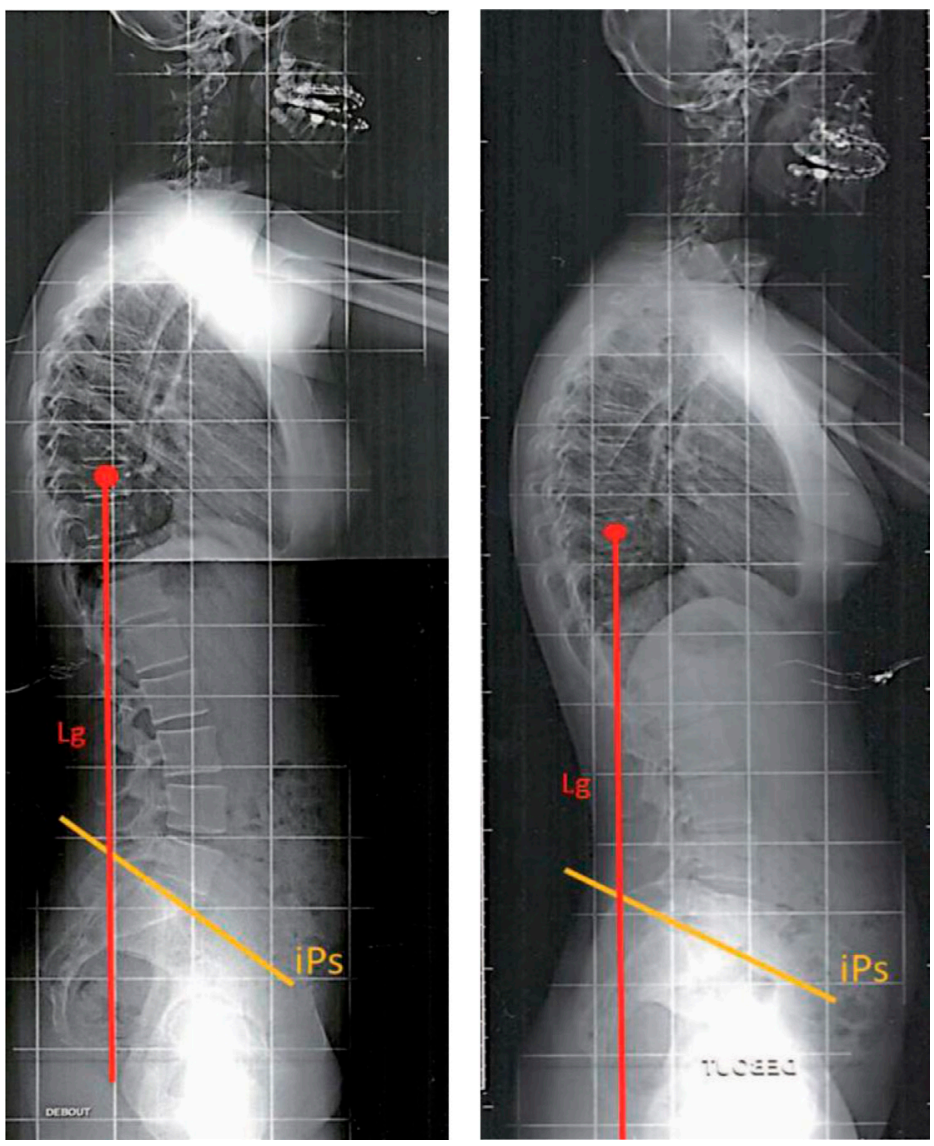

Figure 7

Bimaxillary corrective surgery on skeletal Class III. Retroversion of the pelvis and decrease of sacral plateau tilt in the postoperative period with a more posterior positioning of the body line of gravity.

\section{CONCLUSION}

The orthodontist's field of investigation is increasingly expanding, both in terms of diagnosis and therapy, and must include the patient's postural balance. Anthropology, through the study of the mechanisms leading to the advent of human bipedalism, highlights the impact of verticalization on craniofacial development. The type of balance of the pelvic and spinal organization and the spine pathologies reported in childhood may be able to influence the direction of facial growth. A comprehensive approach to the patient is necessary and the orthodontist must be integrated into multidisciplinary care teams.

Conflict of interest: The authors report no conflict of interest. 


\section{BIBLIOGRAPHY}

1. Achilleos S, Krogstad O, Lyberg T. Surgical mandibu lar setback and changes in uvuloglossopharyngeal morphology and head posture: a short- and long- term cephalometric study in males. Eur J Orthod 2000;22:383-94.

2. Amouroux J, Pirel C, Millet C. Déglutition atypique et troubles posturaux. Chir Dent Fr 2007;13(28):50-7.

3. Arntsen T, Sonnesen L. Cervical vertebral column morphology related to craniofacial morphology and head posture in preorthodontic children with Class-II maloc clusion and horizontal maxillary overjet. Am J Orthod Dentofacial Orthop 2011;140(1):e1-7.

4. Bazert C. Influence de l'avancement de la mandibule sur la posture générale: étude stabilométrique et compléments électromyographiques. Thèse Doct Mécanique. Bordeaux, 2008.

5. Berge C, Gasc JP. Quand la bipédie devient humaine. In: Picq P, Coppens Y. Aux origines de I'humanité, volume 2: Le propre de I'homme. Paris: Ed. Fayard, 2001:80-125.

6. Berthonnaud E, Dimnet J, Roussouly P, Labelle H. Analysis of the sagittal balance of the spine and pelvis using shape and orientation parameters. J Spinal Disord Tech 2005;18(1):40-7.

7. Bouisset $\mathrm{S}$. Biomécanique et physiologie du mouvement. Collection abrégés de médecine, Ed. Masson, 2002, 304 p.

8. Carvalho A, Lazennec JY, Sari-Ali E, Saillant G. Équilibre sagittal du rachis et du complexe lombo-pelvien. Quelles sont les données actuelles? In: Le complexe lombo-pelvien. De I'anatomie à la pathologie, sous la direction de Lazennec JY. Montpellier: Ed. Sauramps Médical, 2005:9-34.

9. Daoulas N, Bazert C, Fabre M, Mesnard M, Boileau MJ. Influence de la modification de I'appui podal sur l'équilibre musculaire cranio-facial. RFOP 2009;4(4):184-88.

10. D'Attilio M, Caputi S, Epifania E, Festa F, Tecco S. Evaluation of cervical posture of children in skeletal classe I, II and III. Cranio 2005;3(23):219-28.

11. Delaire J. Essai d'interprétation des principaux mécanismes liant la statique à la morphogenèse céphalique. Actual Odonto Stomatol 1980;130:189-219.

12. Delattre A, Fenard R. L'hominisation du crâne. Paris: Ed. CNRS, 1960.

13. De Mauroy JC. Évolution paléoantropologique du rachis de I'Homo sapiens. Résonances Européennes du rachis 2007;15(45-46):1863-68.

14. Dufour M, Pullu M. Biomécanique fonctionnelle: membres-tête-tronc. Issy-Les-Moulineaux: Ed. Elsevier Masson, 2006, 568 p.

15. Dujardin F, Tobenas-Dujardin AC, Weber J. Anatomie et physiologie de la marche, de la position assise et debout. Encyclopédie Médico Chirurgicale, Appareil locomoteur 2009:14010-A-10.

16. Duval-Beaupère G, Legaye J. Composante sagittale de la statique rachidienne. Revue du Rhumatisme 2004;71:105-19.

17. Duval-Beaupère G, Schmidt C, Cosson P. A Bary- centremetric study of the sagittal shape of spine and pelvis: the conditions required for an economic standing position. Ann Biomed Eng 1992;20(4):451-62. 
18. Festa $F$, et al. Relationship between cervical lordosis and facial morphology in Caucasian women with a skeletal Class-II malocclusion: a cross-sectional study. Cranio 2003;21(2):121-29.

19. Gagey PM, Weber B. Posturologie, régulation et dérèglements de la station debout, 3e ed. Paris: Ed. Masson, 2005, 199 p.

20. García N, Sanhueza A, Cantin M, Fuentes R. Evaluation of Cervical Posture of Adolescent Subjects in Skeletal Class I, II, and III. Int J Morphol 2012;30(2):405-10.

21. Gareau de Loubresse C, Vialle R, Wolff S. Cyphoses pathologiques. Encyclopédie Médico Chirurgicale, Appareil locomoteur 2008;31-671-C-10.

22. Gommery D. Les grands singes et I'homme ou les car- actéristiques biologiques de I'homme. In: Dutour O. et al. Objets et méthodes en paléoanthropologie. Paris: Comité des travaux historiques et scientifiques 2005, $451 \mathrm{p}$.

23. Gu GM, et al. Hyoid position, pharyngeal airway and head posture in relation to relapse after the mandibular setback in skeletal Class III. Clin Orthod Res 2000;3:67-77.

24. Hellsing E, Reigo T, Mcwilliam J, Spangfort E. Cervical and lumbar lordosis and thoracic kyphosis in 8, 11 and 15-year-old children. Eur J Orthod 1987;9(2):129-38.

25. Joly A. Analyse radiographique de l'équilibre général des patients en classe II squelettique traités par chirur- gie orthognathique. Mémoire CECSMO - Bordeaux, 2013, 77 p.

26. Kapandji Al. Qu'est-ce que la biomécanique? Montpellier: Ed. Sauramps Medical, 2011, $592 \mathrm{p}$.

27. Kylamarkula S, Huggare J. Head posture and the morphology of the first cervical vertebra. Eur J Orthod 1985;7(3):151-56.

28. Legaye J, Duval-Beaupere G, Hecquet J, Marty C. Sagittal equilibration of the spine. Relationship between pelvis and sagittal spinal curves in standing position. Rachis 1993;5(5):215-26.

29. Lippold C, Danesh G, Hoppe G, Drerup B, Hackenberg L. Sagittal spinal posture in relation to craniofacial morphology. Angle Orthod 2006;76(4):625-31.

30. Mangione P, Senegas J. Sagittal balance of the spine. Rev Chir Orthop Repar Appar Mot, 1997;83(1):22-32.

31. Mars an G, Öztas , E, Cura N, Kuvat SV, Emekli U. Changes in head posture and hyoid bone position in Turkish Class III patients after mandibular setback surgery. J Craniomaxillofac Surg 2010;38(2):113-21.

32. Morvan G, Wybier M, Mathieu P, Villemin V, Guerini $H$. Clichés simples du rachis: statique et relations entre rachis et bassin. J Radiol 2008;89:654-66.

33. Özbek MM, Köklü A. Natural cervical inclination and craniofacial structure. Am J Orthod Dentofacial Orthop 1993;104(6):584-91.

34. Pim Valk JW, Zonnenberg AJ, van Maanen CJ, van Wonderen OG. The biomechanical effects of a sagittal split ramus osteotomy on the relationship of the mandible, the hyoid bone and the cervical spine. Am J Orthod Dentofacial Orthop 1992;102(2):99-108.

35. Pirila-Parkkinen K, Lôppônen H, Nieminen P, Tolonen U, Pirttiniemi P. Cephalometric evaluation of children with nocturnal sleep disorders breathing. Eur J Orthod 2010;32(6):662-71.

36. Proust $\mathrm{C}$. Étude des variations de l'équilibre sagittal cranio-rachidien secondaires à la chirurgie orthogna- thique de classe III. Mémoire CECSMO-Bordeaux, 2014, 64 p. 
37. Roussouly P, Berthonnaud E, Dimnet J. Geometrical and mechanical analysis of lumbar lordosis in an asymptomatic population: proposed classification. Rev Chir Orthop Reparatrice Appar Mot 2003;89(7):632-39.

38. Roussouly P, Gollogly S, Berthonnaud E, Dimnet J. Classification of the normal variation in the sagittal alignment of the human lumbar spine and pelvis in the standing position. Spine 2005;30(3):346-53.

39. Sandikcioglu M, Skov S, Solow B. Atlas morphology in relation to craniofacial morphology and head posture. Eur J Orthod 1994;16(2):96-103.

40. Skalli W, Champain S, Mosnier T. Alternatives à l'arthrodèse lombaire et lombosacrée Biomécanique du rachis. Issy-Les-Moulineaux: Ed. Elsevier Masson, 2007:8-18.

41. Solow B, Tallgren A. Head posture and cranio-facial morphology. Am J Phys Anthrop 1977a;47:417-36.

42. Solow B, Sandham A. Cranio-cervical posture: a fac- tor in the development and function of the dentofacial structures. Eur J Orthod 2002;24(5):447-56.

43. Sonnesen L, Petri N, Kjaer I, Svanholt P. Cervical column morphology in adult patients with obstructive sleep apnea. Eur J Orthod 2008;30(5):521-6.

44. Svanholt P, Petri N, Wildschiødtz G, Sonnesen L, Kjaer I. Associations between craniofacial morphology, head posture, and cervical vertebral body fusions in men with sleep apnea. Am J Orthod Dentofacial Orthop 2009;135(6):702.e1-9.

45. Tardieu Ch. Comment sommes-nous devenus bipèdes. Le mythe des enfants-loups. Paris: Odile Jacob, 2012, 220 p.

46. Vialle R, Levassor N, Rillardon L, Templier A, Skalli W, Guigui P. Radiographic analysis of the sagittal alignment and balance of the spine in asymptomatic subjects. J Bone Joint Surg Am 2005,87(2): 260-67.

47. Vidal D. Équilibre sagittal: relations entre les variables morphologiques et posturales de la tête, du rachis, du bassin et des fémurs. Thèse Chirurgiens-dentistes, Bordeaux, 2006, 91 p.

48. Vidal D. Équilibre sagittal: étude statistique sur les rela- tions entre les variables morphologiques et posturales de la tête, du rachis, du bassin et des fémurs. Mémoire CECSMO, Bordeaux, 2011, 90 p.

49. Vital JM, Senagas J, Lavignolle B. Anatomie descriptive et fonctionnelle de la colonne vertébrale. Bordeaux: Ed. Bergeret, 2013, 281 p.

50. Vital JM, Senegas J. Anatomical bases of the study of the constraints to which the cervical spine is subject in the sagittal plane. A study of the center of gravity of the head. Surg Radiol Anat 1986;8(3):169-73.

51. Zepa I, Hurmerinta K, Kovero O, Nissinen M, Kononen M, Huggare J. Associations between thoracic kyphosis, head posture, and craniofacial morphology in young adults. Acta Odontol Scand 2000;58(6):237-42 . 